\title{
VERIFICATION OF THE USEFULNESS OF THE TRIMBLE RTX EXTENDED SATELLITE TECHNOLOGY WITH THE XFILL FUNCTION IN THE LOCAL NETWORK IMPLEMENTING RTK MEASUREMENTS
}

\author{
Zbigniew Siejka \\ University of Agriculture in Krakow, Poland \\ rmsiejka@cyf-kr.edu.pl
}

\begin{abstract}
The paper presents the method of satellite measurements, which gives users the ability of GNSS continuous precise positioning in real time, even in the case of short interruptions in receiving the correction of the local ground system of measurements support. The proposed method is a combination of two satellite positioning technologies RTN GNSS and RTX Extended. In technology RTX Extended the xFill function was used for precise positioning in real time and in the local reference system. This function provides the ability to perform measurement without the need for constant communication with the ground support satellite system. Test measurements were performed on a test basis located in Krakow, and RTN GNSS positioning was done based on the national network of reference stations of the ASGEUPOS.

The solution allows for short (up to 5 minutes) interruptions in radio or internet communication. When the primary stream of RTN correction is not available, then the global corrections Trimble xFill broadcasted by satellite are used. The new technology uses in the real-time data from the global network of tracking stations and contributes significantly to improving the quality and efficiency of surveying works. At present according to the authors, technology Trimble CenterPoint RTX can guarantee repeatability of measurements not worse than $3.8 \mathrm{~cm}$ (Trimble Survey Division, 2012).

In the paper the comparative analysis of measurement results between the two technologies was performed: RTN carried out in the classic way, which was based on the corrections of the terrestrial local network of the Polish system of active geodetic network (ASG-EUPOS) and RTK xFill technology. The results were related to the data of test network, established as error free. The research gave satisfactory results and confirmed the great potential of the use of the new technology in the geodetic work realization. By combining these two technologies of GNSS surveying the user can greatly improve the overall performance of real-time positioning.
\end{abstract}

Keywords: GPS, GNSS, RTX, xFill, coordinate comparison 


\section{INTRODUCTION}

Global navigation and positioning systems are ranked among modern techniques of spatial positioning, which for more than two decades record very dynamic development contributing to the development of many sectors and branches of the world economy. Precise determination of the coordinates of points using differential methods in postprocessing mode on a global scale is known essentially since the system became fully operational (July 1995). GNSS precise positioning in real time on a global scale has become possible only recently. Especially since 2008, when the International GNSS Service (IGS), which is one of the international services of coordinating work of global network of permanent stations work announced open access to the PPP Precise-Point-Positioning service in real time. The PPP service (Rizos, 2012; Huisman 2011) is a method of determining position using global navigation satellite system (GNSS), which uses both pseudorange measurements and phase measurements of the satellite receiver in order to determine the position with high accuracy in any place of the world. This became possible through the use of precise satellite orbit parameters, satellites clocks and other corrections, as atmosphere delays (Jensen and Ovstedal 2008). This gave the possibility to create a wide range of measurement applications. One of them Trimble application Real Time eXtended (RTX) is presented in this paper.

The paper presents the results of the verification of the suitability of a new technology, Trimble RTX with xFill function for precise positioning in real-time RTK in the local reference system. The xFill enables continuity of RTK in case of temporary disconnections of Internet or radio, which are the main cause of the interruption of measurements of kinematic RTK and cause a decrease in reliability and efficiency of this method for determining the position. Presented solution allows for short (up to 5 minutes) interruptions in radio or internet communication. When the elementary stream of RTK corrections is not available then Trimble Global xFill (Leonardo at al., 2012) correction transmitted by satellite is used. The new technology uses real-time data from a global network of tracking stations and contributes significantly to improving the quality and efficiency of surveying works.

At present, according to the creators Trimble CenterPoint RTX technology is designed to ensure repeatability of measurements not worse than $3.8 \mathrm{~cm}$ based on the corrections determined in real-time based on data from a global network of ground reference stations located around the globe (Trimble Survey Division, 2012).

The service is currently available in North America, South America, most of Europe, Russia and the Commonwealth of Independent States, as well as in Africa, Asia and Australia. Corrections of Trimble CenterPoint RTX may be provided directly to the user receiver in one of two ways: through a special satellite or mobile phone network.

If the correction provided by the Internet Protocol (IP) - RTX correcting stream is sent directly to the user through cellular networks, in this case the receiver requires a device that will provide such connectivity. However, in the case of corrections supplied by satellite, the receiver after switching automatically begins tracking RTX correction in a special band (Lband), after a period of several to several tens of minutes, from the satellite a stream of the RTX correction is obtained, that allows to correct the real-time position.

This paper presents the measurement technology, which combines the advantages of a standard technique RTK / RTN based on a local reference stations network with the positioning techniques, which does not require the local reference stations, while ensuring accuracy and efficiency of RTK positioning.

The main aim of this work was to study the accuracy of the proposed by Trimble technology of precise measurements in real time, using the corrections from the global 
network transmitted via satellite and attempt to answer the question whether this technology has the potential for wide application in the practice of surveying and in what time perspective.

\section{GENERAL CONCEPTION OF THE CENTERPOINT RTX SYSTEM}

The RTX technology is dedicated to GNSS positioning at subcentimeter level through the CenterPoint RTX special service company.

The basic infrastructure of the system is shown in Fig. 1 and consists of the following elements:

1. Network of monitoring stations evenly distributed over the globe, linked together by the special Operation Centers.

2. Operating centers located in different places on Earth.

3. Relay stations transmitting corrections to the satellites (Uplink Station)

4. Satellites retransmitting corrections to the Earth

5. Users of the system provided with appropriate GNSS receivers, for example Trimble R10.

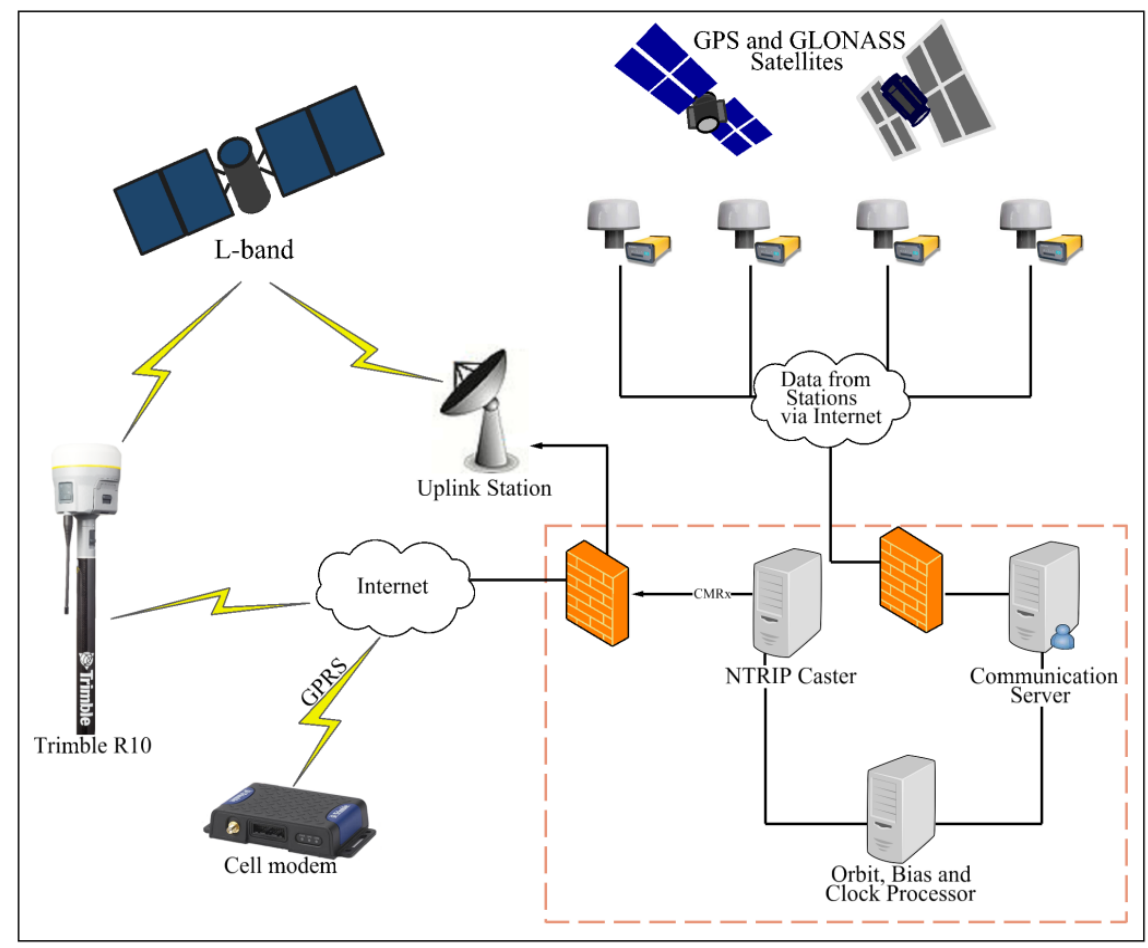

Fig. 1. Infrastructure of the CenterPoint RTX system

Currently Trimble CenterPoint RTX service provides GNSS positioning in real time with global reach and fast initialization. Corrections are transmitted to the Earth through six geostationary satellites using L-band, they can also be accessed via the Internet using NTRIP Caster. The CenterPoint RTX system generates satellite corrections in real time based on streams of data coming from 100 special reference stations of the special monitoring network scattered across the globe Fig. 2.

Since its introduction in 2011, the system has undergone two major modernizations, the first in the spring of 2012 and the second in the spring of 2013. They resulted in a general increase in system efficiency compared to the time of convergence and the introduction of additional services, such as RangePoint RTX and functions, such as xFill. The service Trimble CenterPoint RTX currently supports signals of GPS, GLONASS and QZSS systems. 
Currently, work is underway to assess the possibility of extending the service to include new, additional satellite systems, in particular Galileo and BeiDou.

\section{CONCEPT OF THE IMPLEMENTATION OF THE TEST MEASUREMENTS}

The overall conception of the test measurements is shown in Fig. 2. It was based on the fact, that the kinematic measurements were made on the basis of the primary stream of corrections RTN (VRS) derived from Silesia and Malopolska subnet, which is a part of the ASG-EUPOS network. Field studies were performed on a stationary test point, which coordinates were determined previously using an independent satellite technology, a static method. In the test measurements a satellite receiver Trimble R10 was used. It enables application of the xFill service.

The scientific experiment consisted in the fact that, at first, continuous measurement in real time was activated, based on the elementary stream of the surface corrections RTN with corrections coming from the local ground reference stations network (ASG-EUPOS subnet Silesia-Malopolska). This measurement took 5 minutes. At the time interval of 5 seconds about 60 measurements were made.

Then, arbitrarily, providing with the basic stream of RTN (VRS) corrections was disconnected, and at the same time, R10 Trimble receiver automatically switched to the "xFill" function that filled the gap caused by the lack of the basic correction stream. The transition from RTN to RTX services was done smoothly without losing initialization, while for an operator, on the controller screen, an icon of geostationary satellite appeared, instead of Internet connection icon, and in the lower part the caption "RTK xFill" instead of "RTK" (Fig. 3). The version of Trimble R10 which was used, limited time service "xFill" to 5 minutes in order to protect the user from exceeding the typical threshold values currently required in geodetic measurements.

The measuring experiment designed in this way, was repeated many times in a 24 hour period and thus obtained measurement results were examined in details.

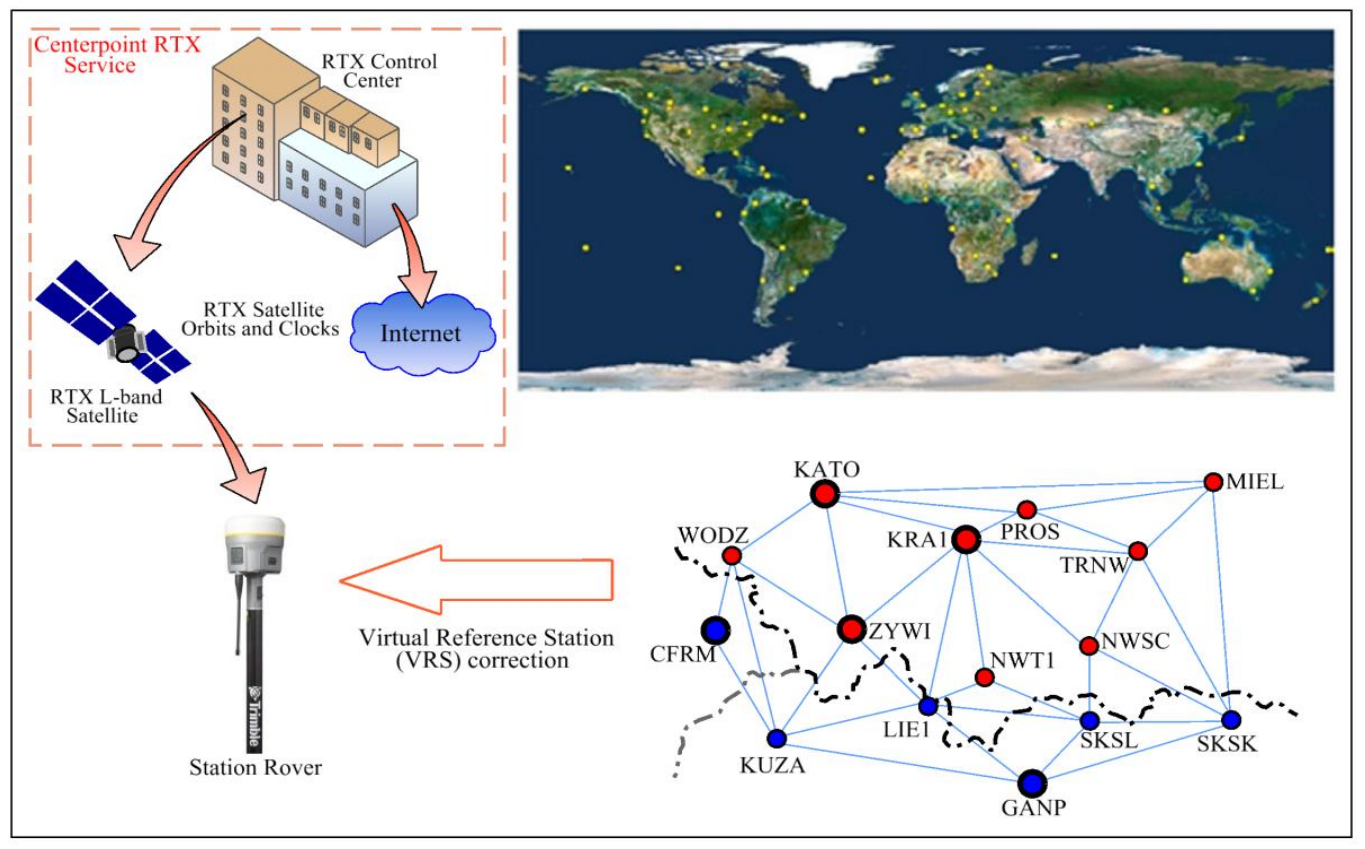

Fig. 2. CenterPoint RTX in cooperation with the local network of reference stations 


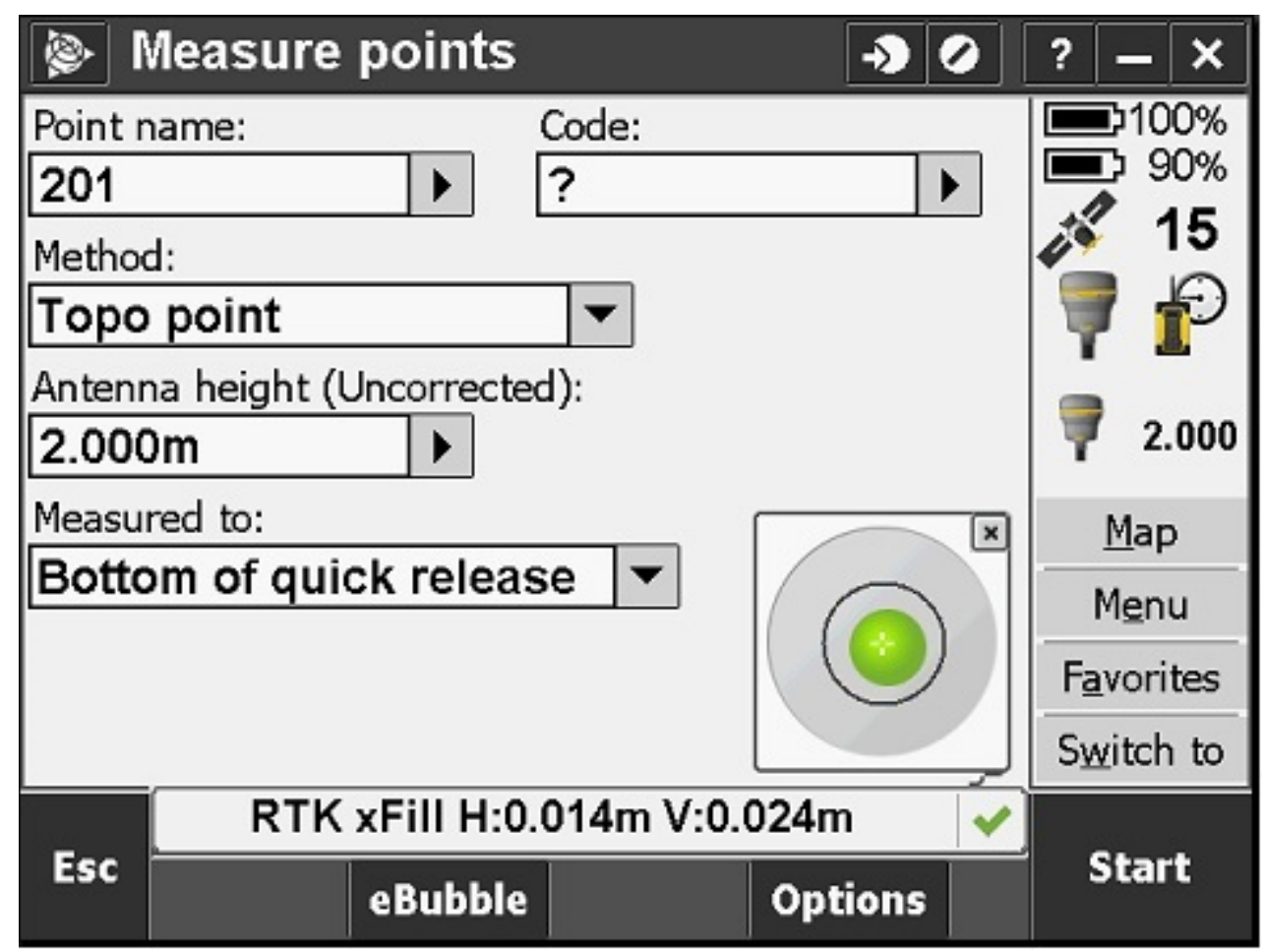

Fig. 3. Sample image of the Trimble R10 receiver controller, of the determination of position, after transition from the RTK solution to RTK xFill

\section{OBTAINED RESEARCH RESULTS}

Test measurements were performed on a stationary control point, located in Krakow approximately $8.8 \mathrm{~km}$ south-east of the reference station KRA1 working in the local ASGEUPOS and in the EPN. The measurement was performed by the RTN technique using the technique of virtual reference station for GPS and GLONASS satellites based on the local Silesia and Malopolska subnet, available in the ASG-EUPOS system. The subnet is active in Poland since April 2011 and provides network corrections for GPS + GLONASS satellites in the area of Silesia and Malopolska in CMRx format. It consists of a total of 15 reference stations. It consists of 9 stations located in Poland (WODZ, KATO, PROS, MIEL, ZYWI, KRA1, TRNW, NWT1, NWSC) and 6 borderland stations, one located in the Czech Republic (CFRM) and 5 in Slovakia (KUZA, LIE1, GANP, SKSL, SKSK) Fig. 2.

In total 48 measuring "session" were performed, each "session" consisted of about 10 minutes of positioning and included 5 minutes of RTN measurement and 5 minutes of RTK xFill measurement. The measurement was performed automatically in the interval of 5 seconds, with a standard angle cutting the horizon of 10 degrees.

During the measurement the following parameters were recorded:

- Determination of the measured point (Number of point)

- Type of the solution (RTN or RTK xFill)

- Antenna Height GNSS

- $3 \mathrm{D}$ coordinates of the measured point $(\mathrm{x}, \mathrm{y}, \mathrm{H})$

- Precision of the determination of the horizontal position (RMS 2D)

- Precision of the determination of the vertical position (RMS 1D)

- The value of the DOP (PDOP) parameter 
- Number of satellites on the basis of which the position was determined (Number of satellites)

- The exact time of the measurement.

Examples of selected investigation results obtained for a single measuring unit are shown in Table 1.

Table 1. Sample research results of selected test investigations

\begin{tabular}{|c|c|c|c|c|c|c|}
\hline \multirow[t]{2}{*}{$\begin{array}{l}\text { Number } \\
\text { of point }\end{array}$} & \multirow[t]{2}{*}{$\begin{array}{l}\text { Type of the } \\
\text { solution }\end{array}$} & \multirow{2}{*}{\begin{tabular}{|c} 
RMS 2D \\
{$[\mathrm{m}]$} \\
\end{tabular}} & \multirow{2}{*}{$\begin{array}{c}\text { RMS 1D } \\
{[\mathrm{mm}]}\end{array}$} & \multirow[t]{2}{*}{ PDOP } & \multirow{2}{*}{$\begin{array}{l}\text { Number } \\
\text { of } \\
\text { satellites. }\end{array}$} & \multirow[t]{2}{*}{ Time } \\
\hline & & & & & & \\
\hline 77770001 & RTN & 0.007 & 0.011 & 1.8 & 10 & $17: 10: 11$ \\
\hline 77770002 & RTN & 0.007 & 0.011 & 1.8 & 10 & $17: 10: 16$ \\
\hline 77770003 & RTN & 0.007 & 0.011 & 1.8 & 10 & $17: 10: 21$ \\
\hline 77770004 & RTN & 0.007 & 0.011 & 1.8 & 10 & $17: 10: 26$ \\
\hline 77770005 & RTN & 0.007 & 0.011 & 1.8 & 10 & $17: 10: 31$ \\
\hline ....... & ....... & ....... & ....... & ....... & ....... & ....... \\
\hline 77770055 & RTN & 0.007 & 0.011 & 1.7 & 11 & $17: 14: 46$ \\
\hline 77770056 & RTN & 0.007 & 0.011 & 1.7 & 11 & $17: 14: 51$ \\
\hline 77770057 & RTN & 0.007 & 0.011 & 1.7 & 11 & $17: 14: 56$ \\
\hline 77770058 & RTN & 0.007 & 0.011 & 1.7 & 11 & $17: 15: 01$ \\
\hline 77770059 & RTN & 0.008 & 0.13 & 1.7 & 11 & $17: 15: 06$ \\
\hline 77770060 & RTN & 0.010 & 0.016 & 1.7 & 11 & $17: 15: 11$ \\
\hline 77770061 & RTKxFill & 0.011 & 0.017 & 1.7 & 11 & $17: 15: 16$ \\
\hline 77770062 & RTKxFill & 0.011 & 0.017 & 1.7 & 11 & $17: 15: 21$ \\
\hline 77770063 & RTKxFill & 0.010 & 0.016 & 1.7 & 11 & $17: 15: 26$ \\
\hline 77770064 & RTKxFill & 0.011 & 0.017 & 1.7 & 11 & $17: 15: 31$ \\
\hline 77770065 & RTKxFill & 0.011 & 0.017 & 1.7 & 11 & $17: 15: 36$ \\
\hline ....... & ....... & ....... & ....... & ....... & ....... & ....... \\
\hline 77770115 & RTKxFill & 0.017 & 0.024 & 1.7 & 11 & $17: 19: 46$ \\
\hline 77770116 & RTKxFill & 0.017 & 0.024 & 1.7 & 11 & $17: 19: 51$ \\
\hline 77770117 & RTKxFill & 0.017 & 0.024 & 1.7 & 11 & $17: 19: 56$ \\
\hline 77770118 & RTKxFill & 0.018 & 0.025 & 1.7 & 11 & 17:20:01 \\
\hline 77770119 & RTKxFill & 0.017 & 0.024 & 1.7 & 11 & $17: 20: 06$ \\
\hline 77770120 & RTKxFill & 0.017 & 0.024 & 1.7 & 11 & 17:20:11 \\
\hline
\end{tabular}

\section{ANALYSIS OF THE ACCURACY OF THE OBTAINED MEASUREMENTS RESULTS}

Altogether 2880 observations were made from the fundamental solution RTN (VRS) and 2832 observations from the RTK xFill solutions. In the first step of analysis for the obtained results, the true measurement errors of coordinates $(\Delta x, \Delta y, \Delta H)$ measured using techniques RTN (VRS) and RTK xFill were calculated as the differences of coordinates $\left(\mathrm{x}_{\mathrm{i}}, \mathrm{y}_{\mathrm{i}}\right.$ and $\left.\mathrm{H}_{\mathrm{i}}\right)$ and the "true" coordinates $\left(\mathrm{x}_{\mathrm{p}}, \mathrm{y}_{\mathrm{p}}, \mathrm{H}_{\mathrm{p}}\right)$ of the control point. Control point coordinates were determined independently using the static method with a millimeter accuracy. Characteristic values of calculated true errors $\left(\Delta_{x}, \Delta_{y}, \Delta_{H}\right)$ and average values of measurements precision calculated by the receiver, and also characteristics of satellite conditions during measurement 
in the form of the Position Dilution of Precision (PDOP) parameter and the number of satellites involved in determining the position are presented in Tables 2 i 3.

In Fig. 4, 5, 6 the true values of errors were shown for the determined coordinates in consecutive in the time measurements, obtained during a single experiment carried out using the combined technology RTN and Trimble RTK xFill. Each diagram contains exactly 5 minutes of RTN positioning and 5 minutes of RTK xFill positioning after disconnecting the primary correction. Diagrams clearly show a progressive decrease of the accuracy of the coordinates in time when using RTK xFill solution.

It should be emphasized that the current version of the R10 receiver limits the use of measurement time to 5 minutes using xFill function or to the selected value of the precision of measurements defined by the user in order to maintain the typical measurement accuracy required currently in geodetic measurements. After exceeding the specified limits or time (5 minutes) of measurement, Trimble Access software automatically interrupts the measurement and the user must restart the supply of the basic stream of RTN corrections to continue measurements.

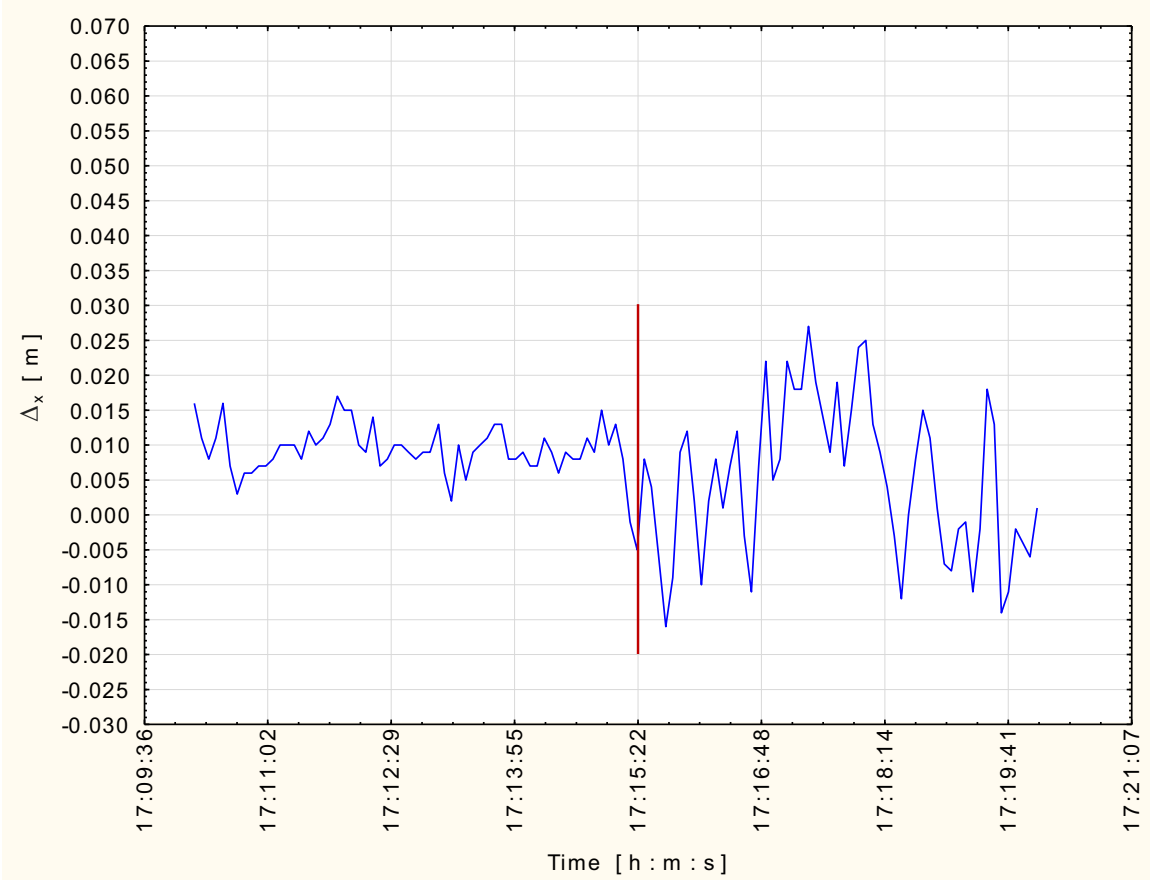

Fig. 4. True errors of $x$-coordinate during the transition from RTN (VRS) solution to RTK xFill 


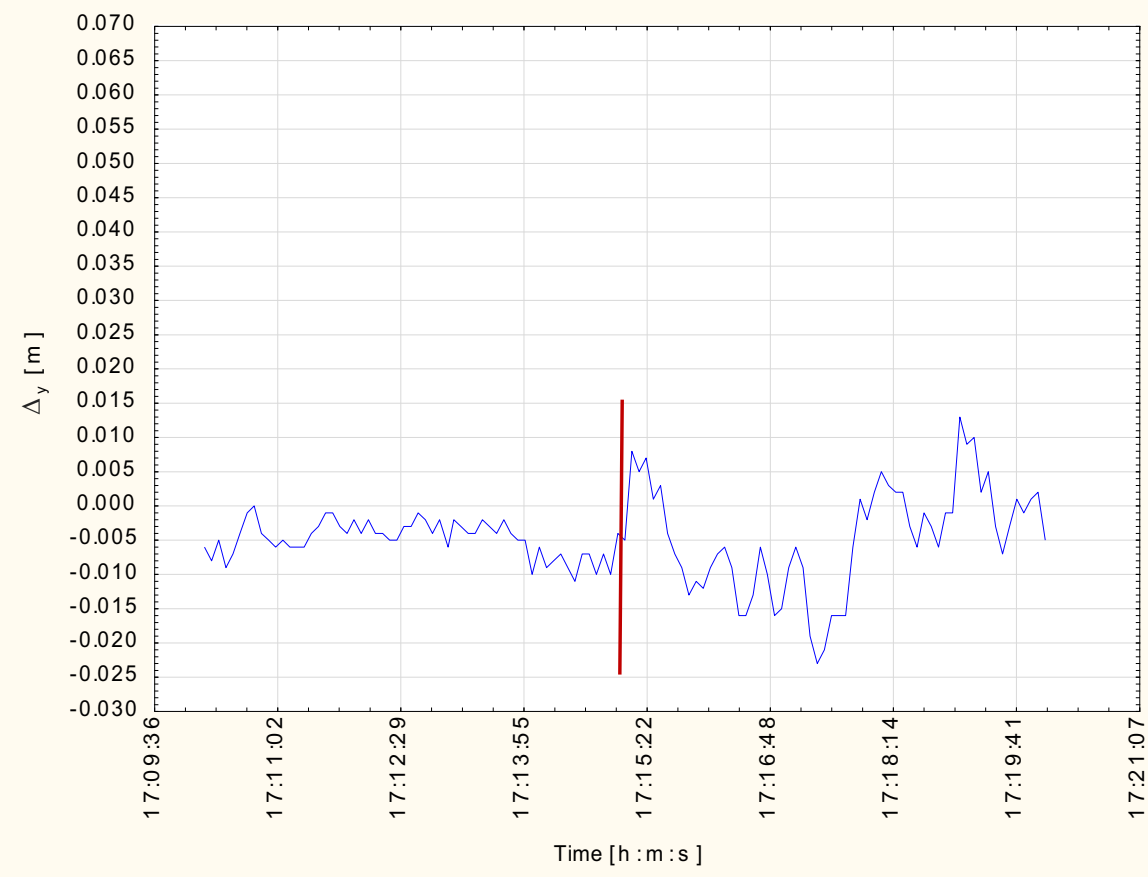

Fig. 5. True errors of y-coordinate during the transition from RTN (VRS) solution to RTK xFill

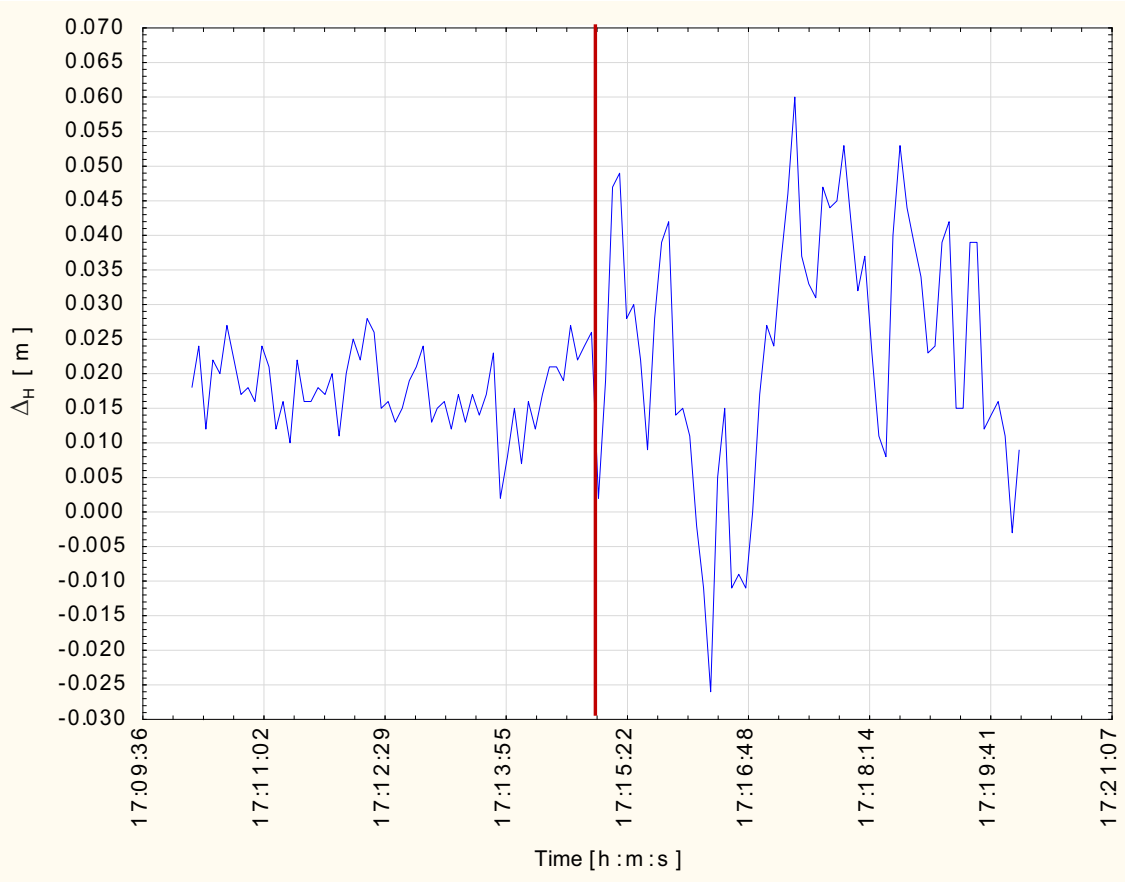

Fig. 6. True errors of $\mathrm{H}$ coordinate during the transition from RTN (VRS) solution to RTK xFill

Next, detailed numerical analysis was made for the results of measurements in two directions. The first direction included assessment of the precision of determined positions given by the receiver during the measurement; the second consisted in the analysis of discrepancies of true errors obtained for measured coordinates. Table 2 contains the average parameters of the obtained measurements and calculations of the fundamental solution which was RTN (VRS), while Table 3 shows the analogous results for the RTK xFill solution. 
Analysis of position determination precision was carried out on the basis of the Root Mean Square Error (RMS), which has been determined to date by the receiver software separately for horizontal position (RMS_2D) and vertical (RMS_1D).

These analyzes showed:

- Average (AVER) decrease of horizontal precision RMS_2D from $7 \mathrm{~mm}$ (Table 2, column 2) to $14 \mathrm{~mm}$ (Table 3, column 2), which represents an increase of $100 \%$

- Average (AVER) decrease of vertical precision RMS_1D from $10 \mathrm{~mm}$ (Table 2, column 3) to $21 \mathrm{~mm}$ (Table 3, column 3), which represents an increase of $110 \%$

These results indicate that the precision of measurements RTK xFill is lower in comparison to the results obtained from the RTN (VRS) solution.

Table 2. List of average values of the true errors obtained from the solution RTN (VRS)

\begin{tabular}{|c|c|c|c|c|c|c|c|c|}
\hline \multirow{3}{*}{ } & \multicolumn{2}{|c|}{$\begin{array}{c}\text { Precision of } \\
\text { determination of a } \\
\text { single measurement }\end{array}$} & \multicolumn{4}{|c|}{$\begin{array}{l}\text { Basic characteristics of the apparent } \\
\text { errors of measurements }\end{array}$} & \multirow{3}{*}{ 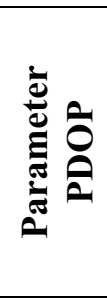 } & \multirow{3}{*}{ 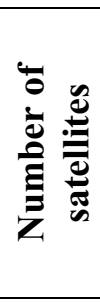 } \\
\hline & RMS_2D & RMS_1D & $\Delta \mathbf{x}$ & $\Delta \mathbf{y}$ & $\Delta p$ & $\Delta_{H}$ & & \\
\hline & {$[\mathrm{mm}]$} & {$[\mathrm{mm}]$} & {$[\mathrm{mm}]$} & {$[\mathrm{mm}]$} & {$[\mathrm{mm}]$} & {$[\mathrm{mm}]$} & & \\
\hline 1 & 2 & 2 & 4 & 5 & 6 & 7 & 8 & 9 \\
\hline MIN & 5 & 7 & -6 & 10 & 2 & -19 & 1.1 & 10 \\
\hline MAX & 13 & 20 & 44 & -21 & 45 & 80 & 2.0 & 19 \\
\hline $\mathrm{R}$ & 8 & 13 & 50 & 31 & 43 & 99 & 0.9 & 9 \\
\hline AVER & 7 & 10 & 14 & -5 & 16 & 24 & 1.4 & 15 \\
\hline$\delta$ & 0.9 & 1.7 & 4.4 & 3.9 & 4.1 & 12.3 & 0.2 & 2 \\
\hline
\end{tabular}

Table 3. List of average values of the true errors obtained from the solution RTK xFill

\begin{tabular}{|c|c|c|c|c|c|c|c|c|}
\hline \multirow{3}{*}{ 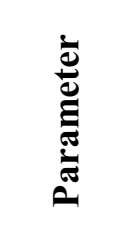 } & \multicolumn{2}{|c|}{$\begin{array}{c}\text { Precision of } \\
\text { determination of a } \\
\text { single measurement }\end{array}$} & \multicolumn{4}{|c|}{$\begin{array}{c}\text { Basic characteristics of the apparent } \\
\text { errors of measurements }\end{array}$} & \multirow{3}{*}{ 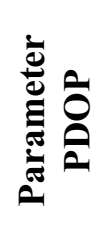 } & \multirow{3}{*}{ 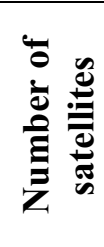 } \\
\hline & RMS_2D & RMS_1D & $\Delta \mathbf{x}$ & $\Delta y$ & $\Delta \mathbf{p}$ & $\Delta_{H}$ & & \\
\hline & {$[\mathrm{mm}]$} & {$[\mathrm{mm}]$} & [mm] & {$[\mathrm{mm}]$} & [mm] & [mm] & & \\
\hline 1 & 2 & 2 & 4 & 5 & 6 & 7 & 8 & 9 \\
\hline MIN & 8 & 12 & -17 & 24 & 0 & -74 & 1.1 & 11 \\
\hline MAX & 22 & 35 & 69 & -41 & 69 & 130 & 2.0 & 19 \\
\hline $\mathrm{R}$ & 14 & 23 & 86 & 65 & 69 & 204 & 0.9 & 8 \\
\hline AVER & 14 & 21 & 15 & -3 & 18 & 25 & 1.4 & 14 \\
\hline$\delta$ & 2.1 & 4.5 & 12.0 & 7.7 & 10.0 & 24.4 & 0.2 & 2 \\
\hline
\end{tabular}

From the analysis of discrepancies (R) listed in Tables 2 and 3 for the measurement results can be seen that:

- The discrepancy of the true errors of measured x coordinates in the RTN solution was 50 mm (Table 2, column 4), while in RTX xFill solution reached $86 \mathrm{~mm}$ (Table 3, column 4), which represents an increase of about $72 \%$.

- The discrepancy of the true errors of measured y coordinates in the RTN solution was 31 mm (Table 2, column 5), while in RTX xFill solution reached $65 \mathrm{~mm}$ (Table 3, column 5), which represents an increase of about $110 \%$. 
- The discrepancy of the true errors of measured height H in the RTN solution was $99 \mathrm{~mm}$ (Table 2, column 7), while in RTX xFill solution reached $204 \mathrm{~mm}$ (Table 3, column 7), which represents an increase of about $110 \%$.

Foregoing analyzes demonstrate empirically, that the actual measurement precision in RTK xFill technology is lower than in the RTN technology.

Maximum true errors of coordinate measurements grew respectively:

- For $\mathbf{x}$ coordinate from: $\Delta x_{R T N}=44 m m$ (Table 2, column 4) for the RTN(VRS) solution to $\Delta_{x_{R T X}}=69 \mathrm{~mm}$ (Table 3, column 4) for the RTK xFill solution(increase of 57\%).

- For $\mathbf{y}$ coordinate from: $\Delta y_{R T N}=21 \mathrm{~mm}$ (Table 2, column 5) for the RTN(VRS) solution to $\Delta y_{R T X}=41 \mathrm{~mm}$ (Table 3, column 5) for the RTK xFill solution (increase of 95\%).

- For $\mathbf{H}$ coordinate from: $\Delta H_{R T N}=80 \mathrm{~mm}$ (Table 2, column 7) for the RTN(VRS) solution to $\Delta H_{R T X}=130 \mathrm{~mm}$ (Table 3, column 7) for the RTK xFill solution (increase of 62\%).

For each coordinate: $x, y, H$, the mean square errors of a single measurement were calculated, according to the formulae:

$$
m_{x}=\sqrt{\frac{\sum_{i=1}^{n}\left(\Delta x_{i} \Delta x_{i}\right)}{n}}, \quad m_{y}=\sqrt{\frac{\sum_{i=1}^{n}\left(\Delta y_{i} \Delta y_{i}\right)}{n}}, \quad m_{H}=\sqrt{\frac{\sum_{i=1}^{n}\left(\Delta H_{i} \Delta H_{i}\right)}{n}}
$$

where: $n$ - is the length of the measurement series,

$\Delta x, \Delta y, \Delta H \quad$ - is a true error of determination of the appropriate point coordinate.

The results are shown in Table 4, column 2 and in Table 5 column 2.

Then the mean square errors of the mean square errors of a single coordinate measurement were calculated according to formulae:

$$
m_{m_{x}}=\frac{m_{x}}{\sqrt{2 n}}, \quad m_{m_{y}}=\frac{m_{y}}{\sqrt{2 n}}, \quad m_{m_{H}}=\frac{m_{H}}{\sqrt{2 n}}
$$

The results are shown in Table 4, column 3 and in Table 5 column 3.

\section{CALCULATION OF APPARENT ERRORS OF COORDINATES MEASUREMENT}

Before proceeding to the second stage of the analysis of measurements results the systematic errors were eliminated, using the classical approach, that the arithmetic mean of a long series of measurements $\left(\mathrm{n}_{1}=2880, \mathrm{n}_{2}=2832\right)$ accurately approximates the true value. Systematic errors were calculated for particular determined coordinates $\left(\delta_{x}, \delta_{y}, \delta_{H}\right)$ respectively:

$$
\delta_{x}=\frac{\sum_{i=1}^{n} \Delta x_{i}}{n}, \quad \delta_{y}=\frac{\sum_{i=1}^{n} \Delta y_{i}}{n}, \quad \delta_{H}=\frac{\sum_{i=1}^{n} \Delta H_{i}}{n}
$$

As it is well known every measurement is affected by a systematic error, irrespectively if one measurement or a series of measurements were done. The sources of systematic errors are primarily imperfection of measurement instruments and the method of measurement applied. These errors act unidirectionally, they add up, therefore even small errors of this type should be carefully eliminated from the measurements. 
Then the apparent errors of measured coordinates were determined $\left(v_{x}, v_{y}, v_{H}\right)$ :

$$
v_{x_{i}}=\Delta x_{i}-\delta_{x}, \quad v_{y_{i}}=\Delta y_{i}-\delta_{y}, \quad v_{H_{i}}=\Delta H_{i}-\delta_{H}
$$

The apparent errors are also present in all the results of the measurement, therefore, when performing repeatedly the measurement received values of the same magnitude differ between each other. The causes of the apparent errors occurrence, are generally not known in detail, they are different in size and sign.

Subsequently apparent average errors of single measurement were calculated for each coordinate $x, y, H$ according to the formulae:

$$
m_{v_{x}}=\sqrt{\frac{\sum_{i=1}^{n}\left(v_{x_{i}} v_{x_{i}}\right)}{n}}, \quad m_{v_{y}}=\sqrt{\frac{\sum_{i=1}^{n}\left(v_{y_{i}} v_{y_{i}}\right)}{n}}, \quad m_{v_{H}}=\sqrt{\frac{\sum_{i=1}^{n}\left(v_{H_{i}} v_{H_{i}}\right)}{n}}
$$

Finally, the mean errors of apparent mean errors of single measurements of coordinates were calculated as:

$$
m_{m_{m_{x}}}=\frac{m_{v_{x}}}{\sqrt{2 n}}, \quad m_{m_{m_{y}}}=\frac{m_{v_{y}}}{\sqrt{2 n}}, \quad m_{m_{m_{H}}}=\frac{m_{v_{H}}}{\sqrt{2 n}}
$$

All the results of the calculations are shown in Tables 4 and 5 .

Table 4. Summary of errors obtained from the RTN (VRS) solution

\begin{tabular}{|c|c|c|c|c|}
\hline & $\begin{array}{c}\text { True mean error of a } \\
\text { single coordinate } \\
\text { measurement } \\
\left(m_{x}, m_{y}, m_{H}\right)\end{array}$ & $\begin{array}{c}\text { Mean error, of the } \\
\text { true mean error of } \\
\text { a single } \\
\text { measurement of the } \\
\text { coordinate } \\
\left(m_{m_{x}}, m_{m_{y}}, m_{m_{H}}\right)\end{array}$ & $\begin{array}{c}\text { The mean apparent } \\
\text { error of a single } \\
\text { measurement of the } \\
\text { adjusted coordinate } \\
\left(m_{v_{x}}, m_{v_{y}}, m_{v_{H}}\right)\end{array}$ & $\begin{array}{c}\text { Mean error, of the } \\
\text { mean apparent error } \\
\text { of a single } \\
\text { measurement of the } \\
\text { adjusted coordinate } \\
\left(m_{m_{m_{x}}}, m_{m_{m_{y}}}, m_{m_{m_{H}}}\right)\end{array}$ \\
\hline $\mathrm{U}$ & 2 & 3 & 4 & 5 \\
\hline $\mathrm{x}$ & {$[\mathrm{mm}]$} & {$[\mathrm{mm}]$} & {$[\mathrm{mm}]$} & {$[\mathrm{mm}]$} \\
\hline $\mathrm{y}$ & 6 & 0.21 & 4 & 0.06 \\
\hline $\mathrm{H}$ & 27 & 0.09 & 4 & 0.05 \\
\hline
\end{tabular}

Table 5. Summary of errors obtained from the RTK xFill solution

\begin{tabular}{|c|c|c|c|c|}
\hline & $\begin{array}{c}\text { True mean error of a } \\
\text { single coordinate } \\
\text { measurement } \\
\left(m_{x}, m_{y}, m_{H}\right)\end{array}$ & $\begin{array}{c}\text { Mean error, of the } \\
\text { true mean error of } \\
\text { a single } \\
\text { measurement of the } \\
\text { coordinate } \\
\left(m_{m_{x}}, m_{m_{y}}, m_{m_{H}}\right)\end{array}$ & $\begin{array}{c}\text { The mean apparent } \\
\text { error of a single } \\
\text { measurement of the } \\
\text { adjusted coordinate } \\
\left(m_{v_{x}}, m_{v_{y}}, m_{v_{H}}\right)\end{array}$ & $\begin{array}{c}\text { Mean error, of the } \\
\text { mean apparent error } \\
\text { of a single } \\
\text { measurement of the } \\
\text { adjusted coordinate } \\
\left(m_{m_{m_{x}}}, m_{m_{m_{y}}}, m_{m_{m_{H}}}\right)\end{array}$ \\
\hline 1 & 2 & 3 & 4 & 5 \\
\hline $\mathrm{x}$ & {$[\mathrm{mm}]$} & {$[\mathrm{mm}]$} & {$[\mathrm{mm}]$} & {$[\mathrm{mm}]$} \\
\hline $\mathrm{y}$ & 19 & 0.27 & 12 & 0.17 \\
\hline $\mathrm{H}$ & 3 & 0.12 & 8 & 0.11 \\
\hline
\end{tabular}


According to Table 4 and 5, we conclude that the determined mean errors of the meansquare errors of individual measurements of coordinates do not exceed their triple value which indicates the proper accuracy of measurements and calculations.

The following diagrams in accordance with the measurement and Table 1 show:

1. True errors distribution for each coordinate as $\left(\Delta_{x}, \Delta_{y}, \Delta_{H}\right)($ Fig. 7, 8, 9) in the solution with the use of the RTN technology.

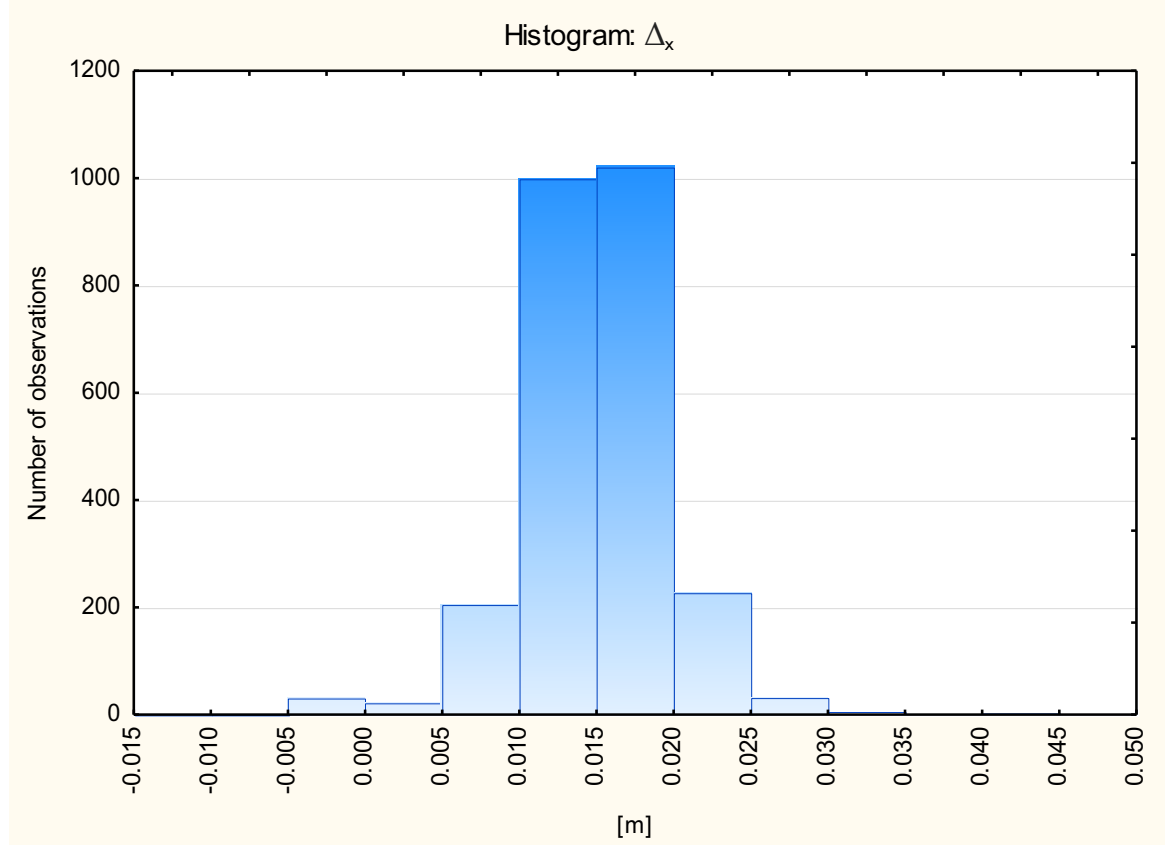

Fig. 7. The distribution of true errors of $x$ coordinate determination in the RTN solution

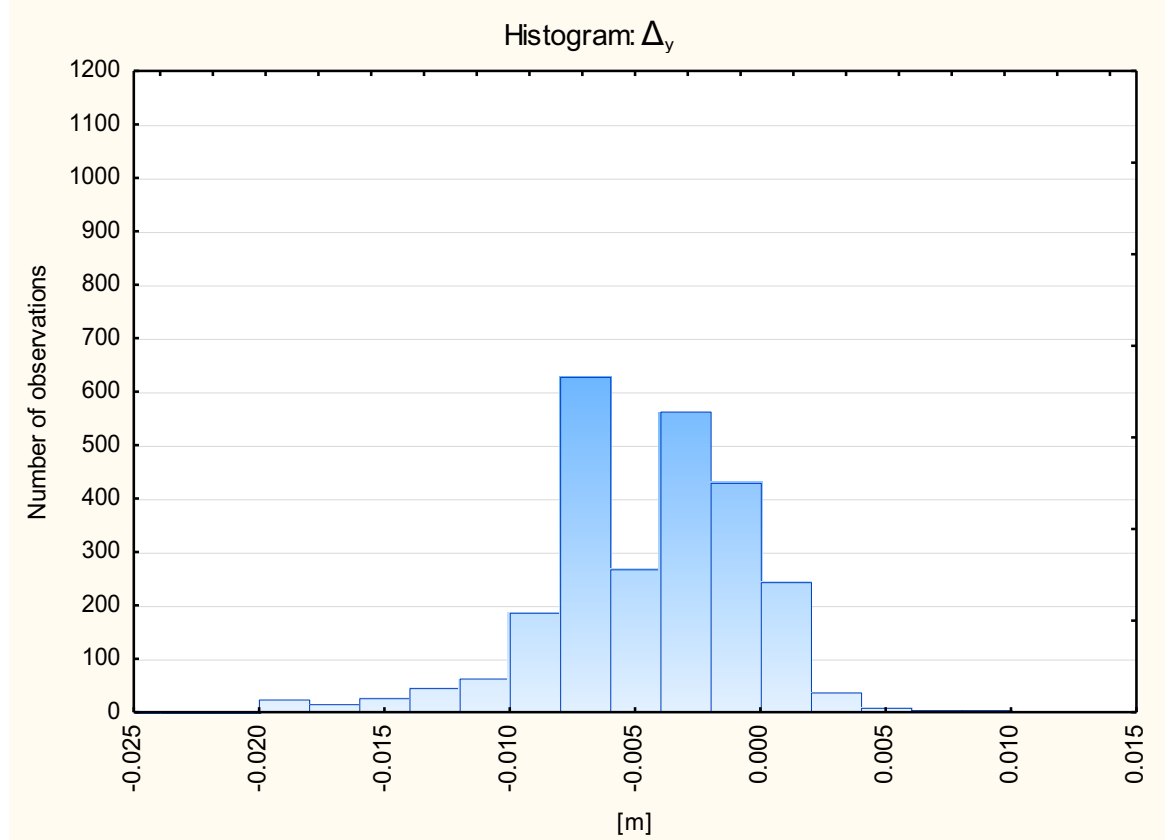

Fig. 8. The distribution of true errors of y coordinate determination in the RTN solution 


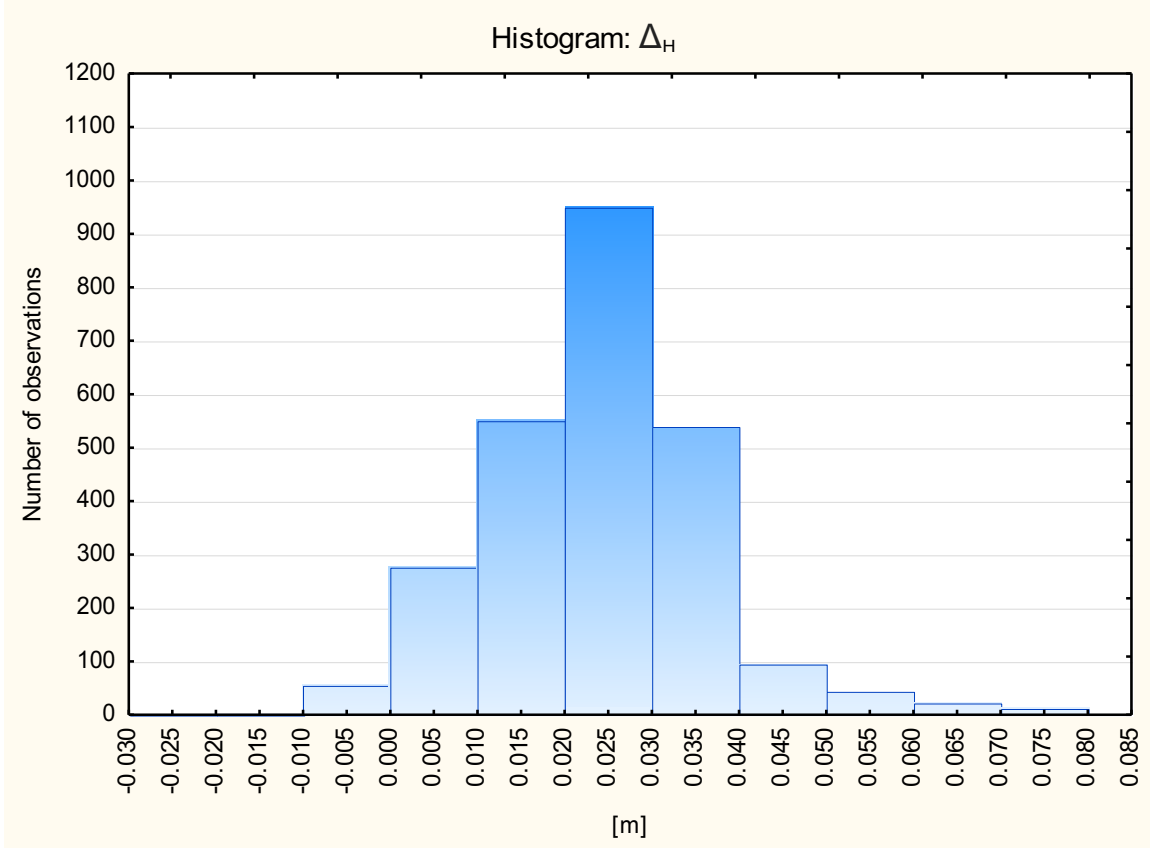

Fig. 9. The distribution of true errors of $\mathrm{H}$ coordinate determination in the RTN solution

In all cases, the histograms indicate that there are significant systematic errors of each coordinate determination at subcentimeter level.

2. Apparent errors distribution for each coordinate as $\left(\Delta_{\mathrm{x}}, \Delta_{\mathrm{y}}, \Delta_{\mathrm{H}}\right)($ Fig. 7, 8, 9) in the solution with the use of the RTN technology

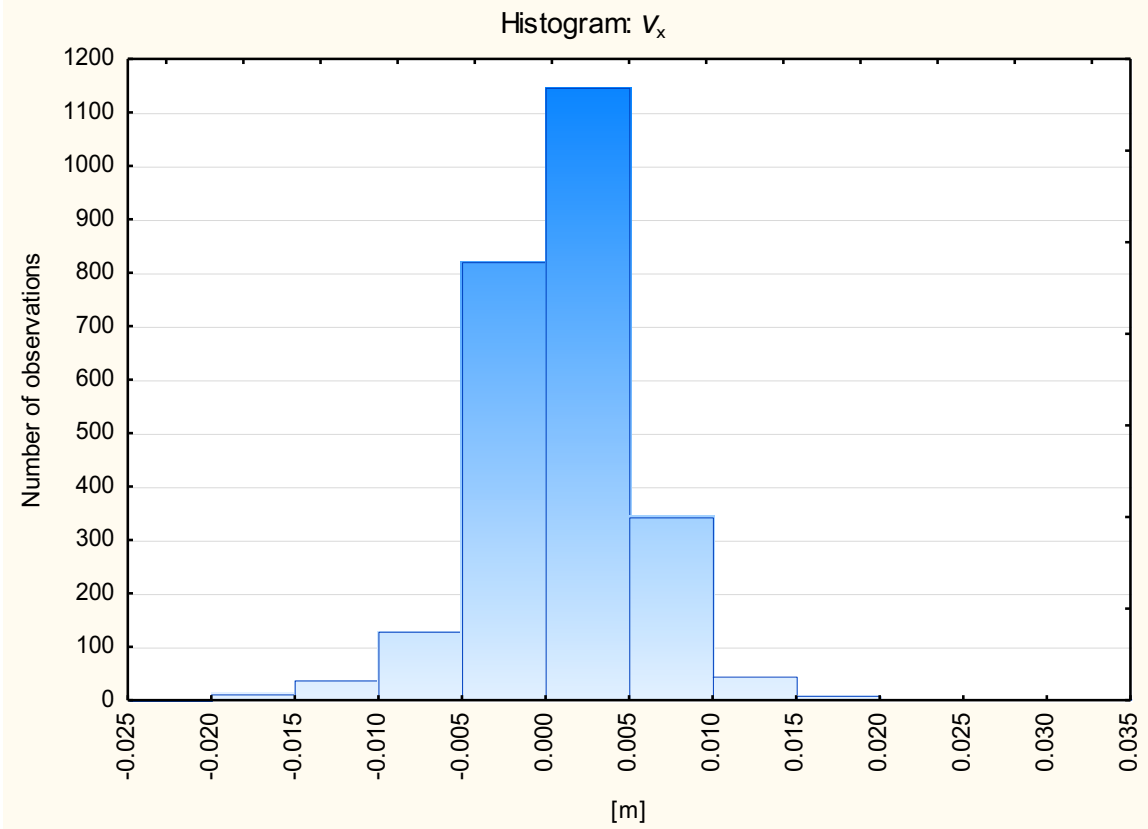

Fig. 10. The distribution of apparent errors of $x$ coordinate determination in the RTN solution 


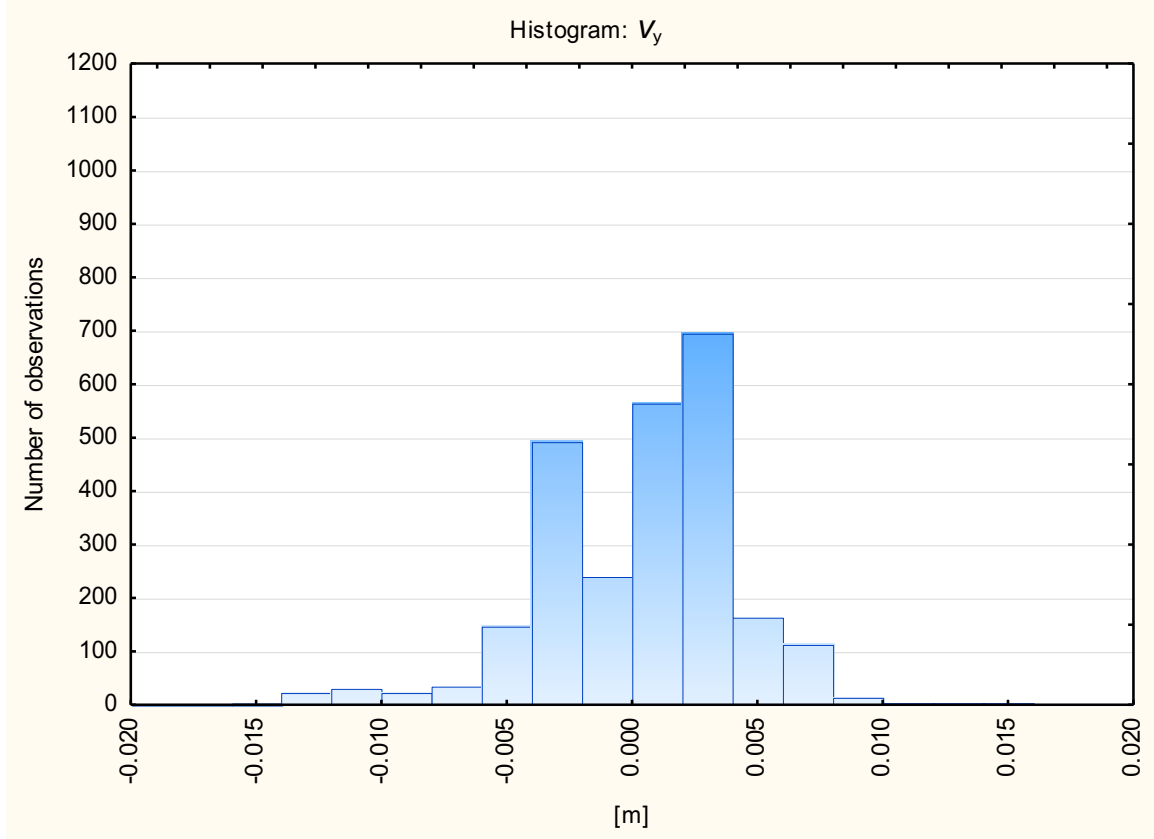

Fig. 11. The distribution of apparent errors of y coordinate determination in the RTN solution

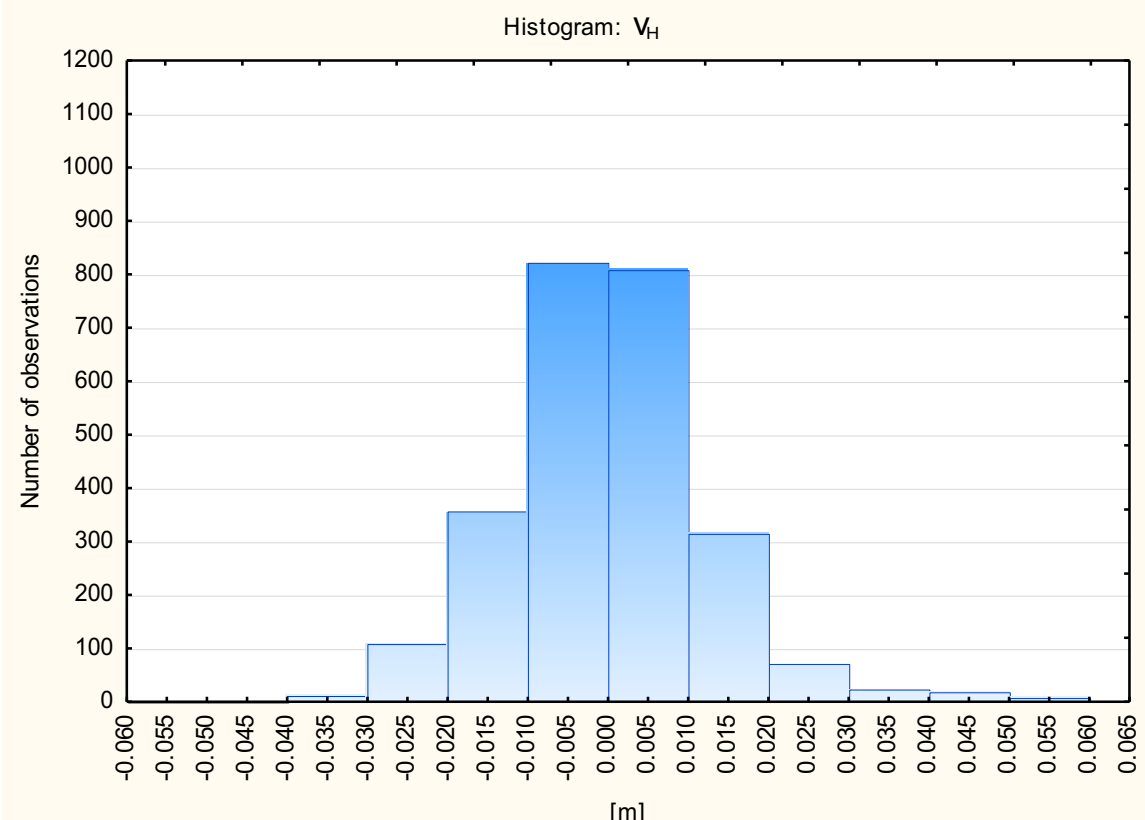

Fig. 12. The distribution of apparent errors of $\mathrm{H}$ coordinate determination in the RTN solution

In all these cases, we note the absence of systematic errors of each coordinate determination, what confirms the appropriate elimination of systematic errors.

3. True errors distribution $\left(\Delta_{\mathrm{x}}, \Delta_{\mathrm{y}}, \Delta_{\mathrm{H}}\right)$, for single coordinates measurement (Fig. 13, 14, 15) in the solution based on RTK xFill technology. 


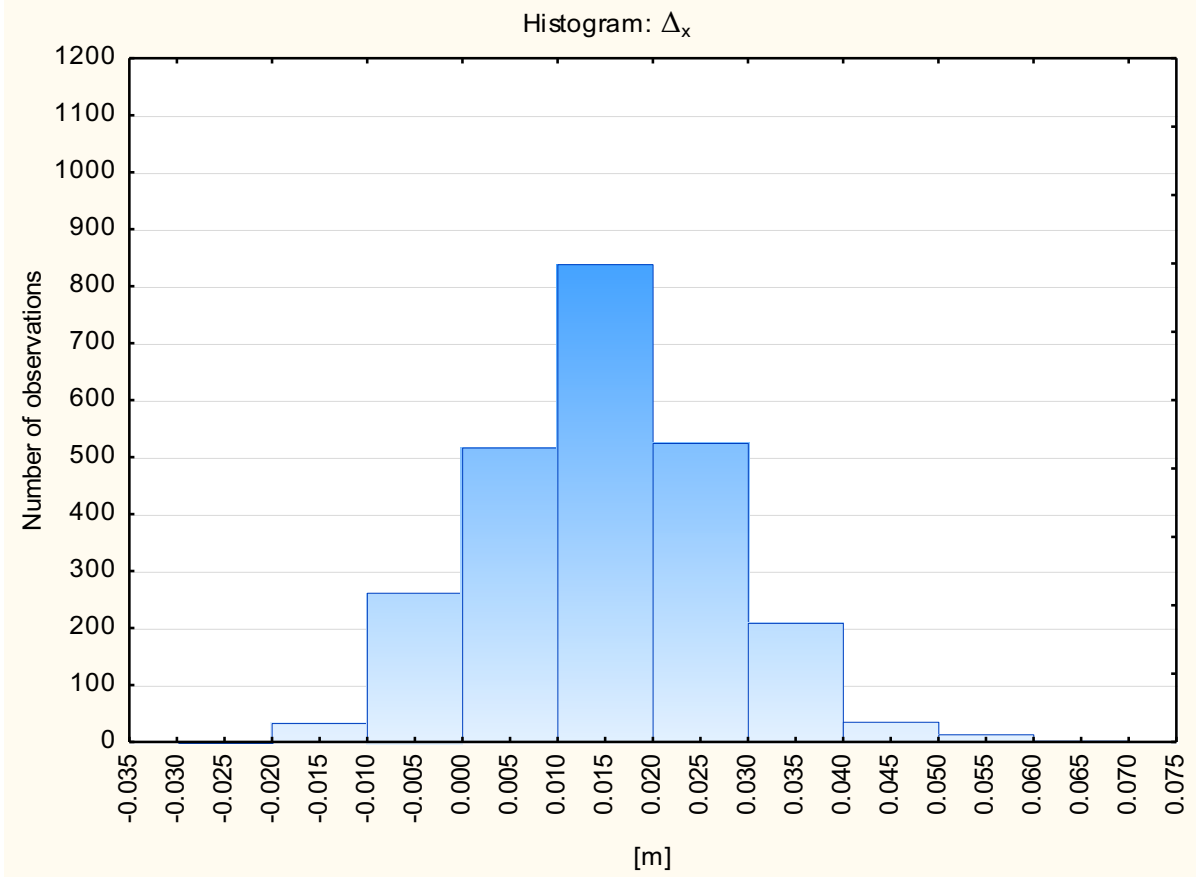

Fig. 13. The distribution of true errors of $x$ coordinate determination in the RTN xFill solution

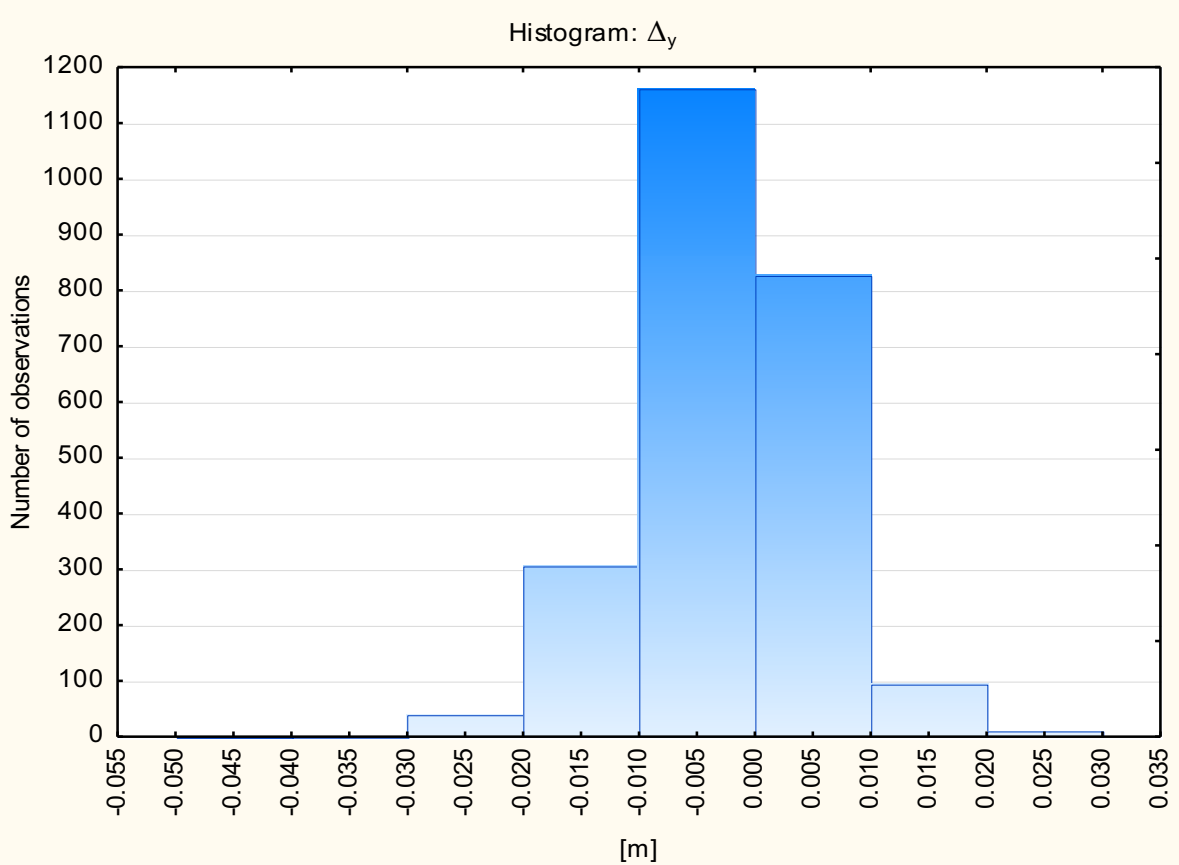

Fig. 14. The distribution of true errors of y coordinate determination in the RTN xFill solution 


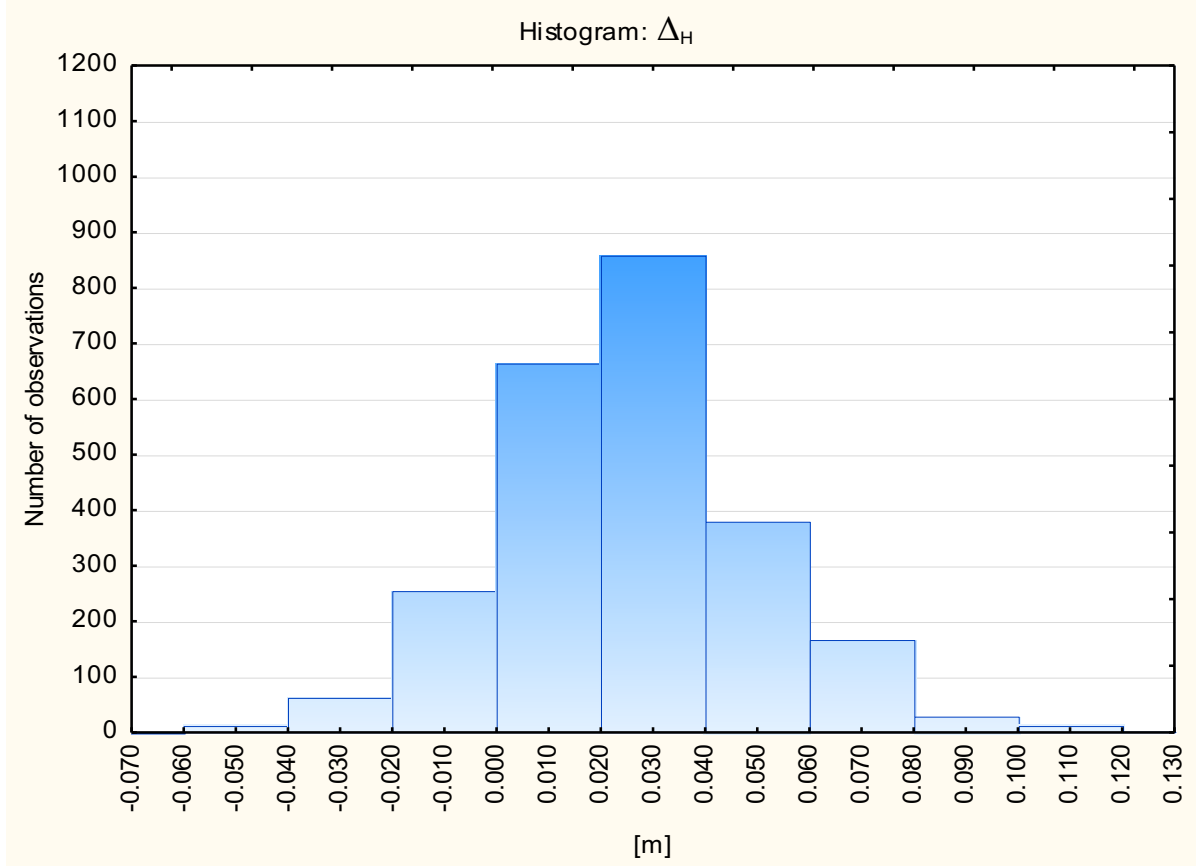

Fig. 15. The distribution of true errors of $\mathrm{H}$ coordinate determination in the RTN xFill solution 4. Apparent errors distribution $\left(\Delta_{\mathrm{x}}, \Delta_{\mathrm{y}}, \Delta_{\mathrm{H}}\right)$, for single coordinates measurement (Fig. 16, 17, 18) in the solution based on RTK xFill technology.

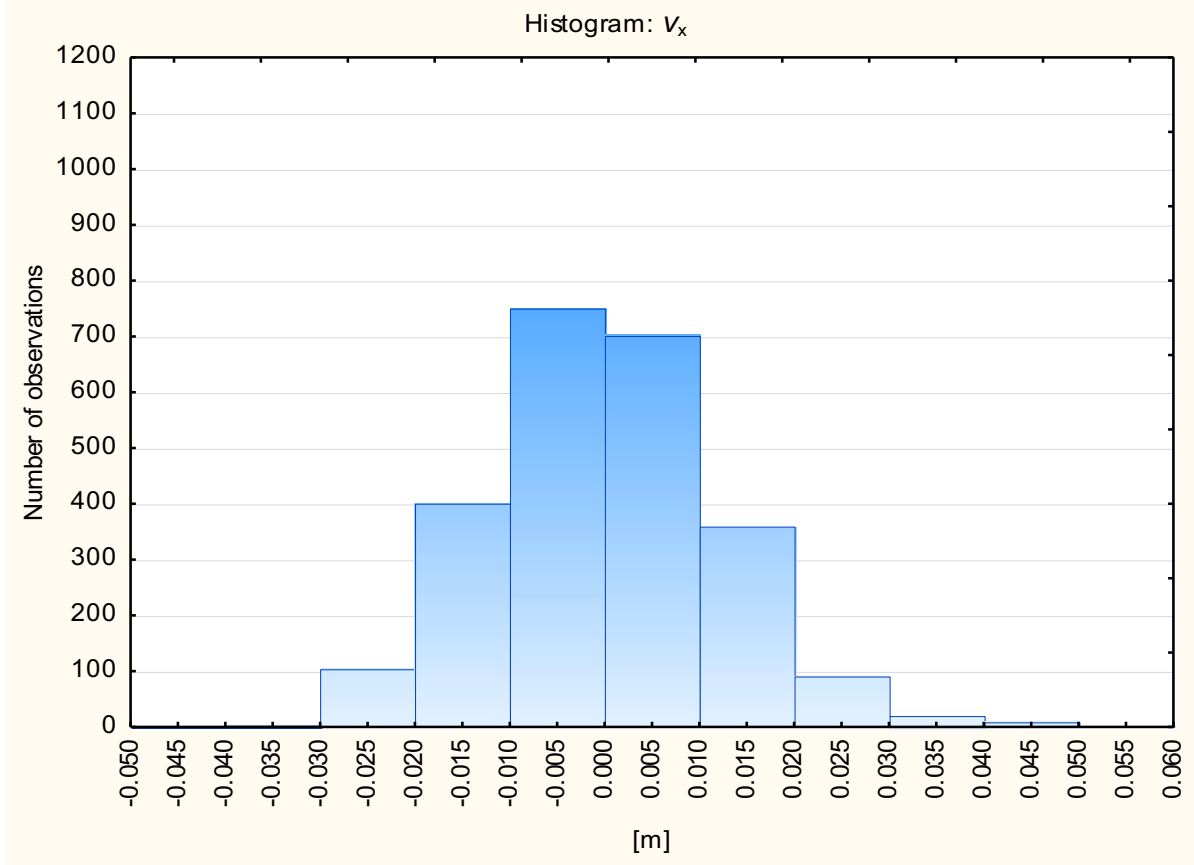

Fig. 16. The distribution of apparent errors of $x$ coordinate determination in the RTN xFill solution 


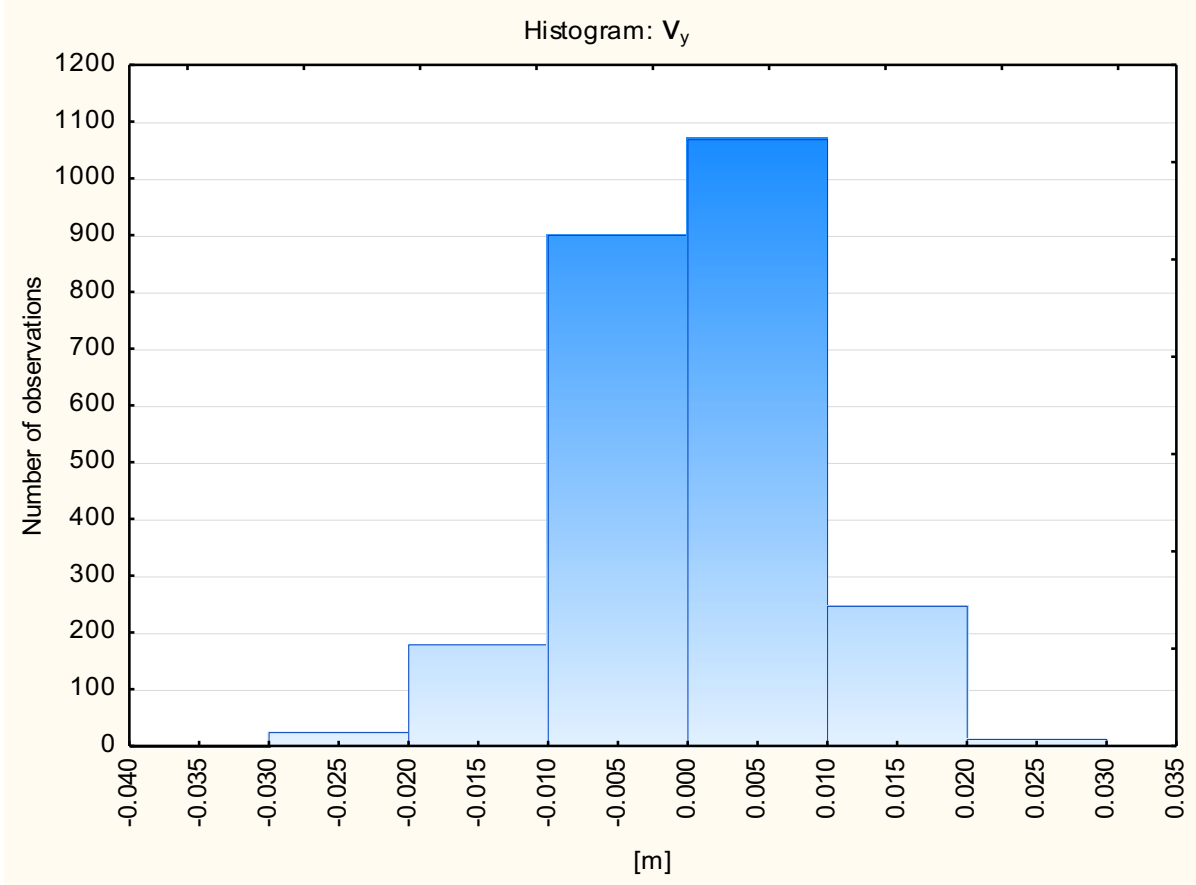

Fig. 17. The distribution of apparent errors of y coordinate determination in the RTN xFill solution

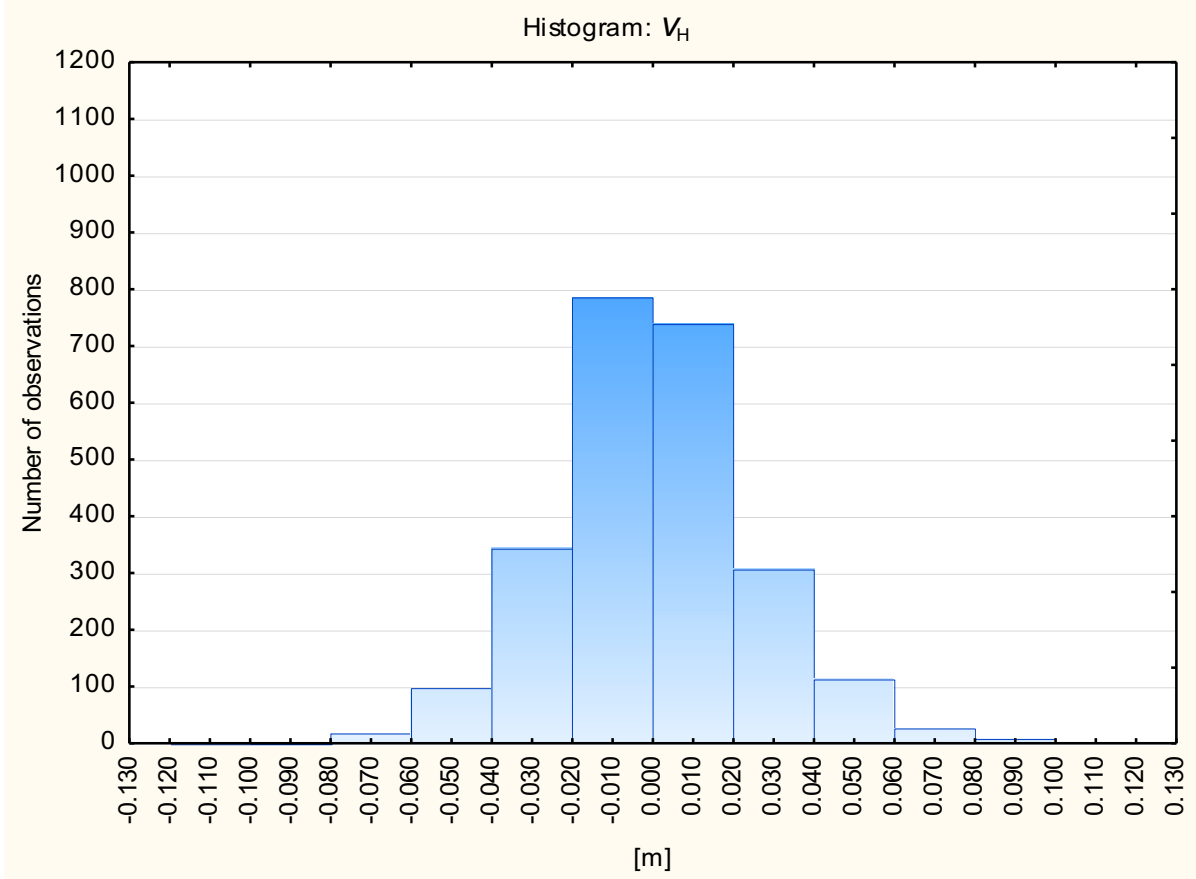

Fig. 18. The distribution of apparent errors of $\mathrm{H}$ coordinate determination in the RTN xFill solution

\section{CONCLUSIONS}

1. Trimble xFill is a new technology that at the present day allows for a short time to continue the satellite measurements in real time in the absence of corrections data stream from reference stations network or a single base station to the mobile receiver rover. This affects significantly the increase of the efficiency of the measurement by reducing gaps in measurement resulting from the interruption in the GSM or radio transmission. It was 
shown in the paper that the Trimble R10 is able to continue real-time measurements in the case of short interruptions (for 5 minutes) in the radio or Internet link with a network of ground reference stations. There were no delays in the event of loss of Internet connection and the receiver automatically and seamlessly activated the job using RTK xFill services.

2. On the basis of empirical research, in a fully opened horizon, an average decrease of the accuracy of the position determination, was shown respectively:

- for x coordinate: RTN $+5 \mathrm{~mm} /$ minute,

- for y coordinate: RTN $+4 \mathrm{~mm} /$ minute,

- for H coordinate: RTN $+10 \mathrm{~mm} /$ minute.

It should be noted that both for the horizontal position as well as for the height determination the results are much better than the results reported officially by the owner of the service company Trimble. The study also showed that for the plane coordinates determined on the basis of the RTK xFill solution more than $90 \%$ of the observations were characterized by the point position error $<0.05 \mathrm{~m}$. However, less than $60 \%$ of measurements were characterized by the height determination error $\mathrm{M}_{\mathrm{H}}<0.10 \mathrm{~m}$.

3. Basing on the analysis of mean square errors in both solutions significant systematic errors at a level from 4 to $11 \mathrm{~mm}$ were found. These errors can be divided into two basic groups: errors constant in time and errors changing in time. The concept of test measurements carried out in the work enables the elimination of the errors fixed in time (eg. antenna calibration errors, errors of GNSS receivers). However, in order to remove the time-varying errors resulting primarily from insufficient elimination of the ionosphere and troposphere errors [5] the analogous test measurements should be performed for extra points with different conditions for satellites observations. To ensure accurate and fully correct results of observations, all systematic errors should be eliminated from the final results. Conducting a detailed analysis of diagrams it can be concluded that the errors in the coordinates $\mathrm{x}$ and $\mathrm{H}$ in RTN and $\mathrm{xFill}$ solutions show normal distribution. With respect to the $\mathrm{Y}$ coordinate it should be noted that in the case of the solution obtained with the use of RTN technology distributions of the true and apparent errors are different from the normal distribution (for about 250 measurements, Fig. 8 and 11) which is about $15 \%$ of the total number of observations and practically does not affect the accuracy of the determination of y coordinate.

4. In the nearest future, the author plans to carry out measurements on other reference points in different satellite conditions (greater and lesser), also using other receivers. Also the extension of the measurement with the use of xFill technology to 10 minutes is interesting. The obtained results confirm indeed such possibility. I can see the need and the sense of continuing research in this area, because used in the research RTK xFill solution allowed to avoid interruptions in the field measurement, resulting from interruptions of basic correction transfer from the ground system of satellite measurements support in real (RTN - using mobile Internet) for satellite support system (RTK xFill). This had a significant impact on improving the effectiveness and efficiency of surveying field work. The results of research also show that in the nearest future the local reference station networks will lose their significance for the "sparse" but more accurate and higher-tech advanced global networks. 


\section{REFERENCES}

Huisman L., Teunissen P.J.G. and Hu C. (2012). GNSS precise point positioning in regional reference frames using real-time broadcast corrections. Journal of Applied Geodesy, Vol. 6, pp. $15-23$

Jensen A.B.O., Ovstedal O. (2008). THE EFFECT OF DIFFERENT TROPOSPHERIC MODELS ON PRECISE POINT POSITIONING IN KINEMATIC MODE. Survey Review, 40, 308 pp. 173-178

Leandro R., Landau H., Nitschke M., Glocker M., Seeger S., Chen X., Deking, A., Tahar M.B., Zhang F., Ferguson K., Stolz R., Talbot N., Lu G., Allison A., Brandl M., Gomez V., Cao W., Kipka A. (2012). RTX Positioning: The Next Generation of cm-accurate Real-Time GNSS Positioning Trimble Terrasat GmbH, Germany

Rizos C., Janssen V., Roberts C. and Grinter T. (2012). Precise Point Positioning: Is the Era of Differential GNSS Positioning Drawing to the End. FIG Working Week, Rome, Italy, TS09B

Trimble Survey Division (2012). White Paper. Westminster, Colorado, USA, www.trimble.com

Received: 2014-09-25,

Reviewed: 2014-11-17, by K. Tretyak,

Accepted: 2014-12-01. 